\title{
EKSPLORASI ETNOMATEMATIKA PADA MOTIF BATIK LEBAK DILIHAT DARI SISI NILAI FILOSOFI DAN KONSEP MATEMATIS
}

\author{
Isnaini Mahuda ${ }^{1}$ \\ ${ }^{1}$ Universitas Bina Bangsa, Serang \\ isnaini.mahuda@binabangsa.ac.id ${ }^{1}$
}

\begin{abstract}
Ethnomatematics is a link between ethnography and mathematics. In other words, ethnomatematics studies about mathematics applied in a cultural group. Indonesia is a rich country in cultural heritage. One of Indonesia's cultural heritages recognized internationally by UNESCO is batik. We should as Indonesian people have to protect and preserve batik culture so that it will not be lost in time or even claimed as a culture of another country. The effort to preserve batik culture is to get to know the types of batik that exist in Indonesia. One type of batik in Indonesia, especially in the province of Banten is Batik Lebak. Batik Lebak was first launched in 2016 and already has 12 patented motifs. The motifs consist of the name Kahuripan Baduy motif, Seren Taun motif, Sawarna motif, Angklung Buhun motif, Caruluk Saruntuy motif, Sakojor Sugar motif, Lebak Bertauhid motif, Kalimaya motif, Rangkasbitung motif, Pare Sapocong motif, Leuit Sijimat motif, and Sadulur motif. The purpose of this study is to explore and to describe the philosophical values of the Batik Lebak motif related with mathematical concepts. This research is a qualitative research with ethnographic approach. The results of the study were obtained that in addition to having philosophical values, motifs on Batik Lebak are related to mathematical concepts, namely symmetrical concepts, concepts of congruence and similarity and concepts on geometrical transformations consisting of concepts of translation, reflection, rotation and also dilatation.
\end{abstract}

Keywords: Ethnomatematics, Lebak Batik Motifs, Philosophical Values, and Mathematical Concepts

\begin{abstract}
Abstrak
Etnomatematika merupakan irisan antara etnografi dan matematika. Dengan kata lain, etnomatematika ini mengkaji ilmu matematika yang diterapkan dalam suatu kelompok budaya. Indonesia merupakan negara yang kaya akan warisan budaya. Salah satu warisan budaya Indonesia yang diakui secara internasional oleh UNESCO adalah batik. Sudah semestinya kita sebagai bangsa Indonesia wajib menjaga dan melestarikan kebudayaan batik agar tidak hilang ditelan zaman atau bahkan diklaim sebagai budaya milik negara lain. Salah satu upaya untuk menjaga dan melestarikan budaya batik adalah dengan mengenal jenisjenis batik yang ada di Indonesia. Salah satu jenis batik yang ada di Indonesia khususnya di Provinsi Banten yaitu Batik Lebak. Batik Lebak pertama kali diluncurkan pada tahun 2016 dan telah memiliki 12 motif yang telah dpatenkan. Motif-motifnya terdiri atas nama motif Kahuripan Baduy, motif Seren Taun, motif Sawarna, motif Angklung Buhun, motif Caruluk Saruntuy, motif Gula Sakojor, motif Lebak Bertauhid, motif Kalimaya, motif Rangkasbitung, motif Pare Sapocong, motif Leuit Sijimat, dan motif Sadulur. Adapun tujuan penelitian ini adalah untuk mendeskripsikan nila-nilai filosofis pada motif batik Lebak dan juga kaitannya dengan konsep matematis. Penelitian ini merupakan penelitian kualitatif dengan pendekatan etnografi. Hasil dari penelitian diperoleh bahwa selain memiliki nilai-nilai filosofis, motif pada batik Lebak juga memiliki keterkaitan dengan konsep matematis yaitu konsep simetris, konsep kesebangunan dan kekongruenan serta konsep pada transformasi geometris yang terdiri dari konsep translasi, refleksi, rotasi dan juga dilatasi.
\end{abstract}

Kata Kunci: Etnomatematika, Motif Batik Lebak, Nilai Filosofis, dan Konsep Matematis

Received: January 10, 2020 / Accepted: April 25, 2020 / Published Online: April 30, 2020 
Jurnal Lebesgue : Jurnal Ilmiah Pendidikan Matematika, Matematika dan Statistika

Isnaini Mahuda

Volume 1, No. 1, April 2020 hal.29-38

\section{PENDAHULUAN}

Matematika tidak hanya dipelajari secara formal di lingkungan sekolah akan tetapi sebenarnya matematika begitu dekat dengan kehidupan kita. Sayangnya banyak diantara kita yang tidak menyadari akan hal tersebut. Secara tidak langsung masyarakat telah mengenal matematika dalam aktifitas keseharian yang mereka lakukan misalnya menghitung, mengukur, memberi pola, dan masih banyak lagi. Aktifitas keseharian akan membentuk suatu kebiasaan yang menunjukan budaya dari sekelompok masyarakat. Keterkaitan antara budaya dan konsep matematika inilah yang disebut sebagai etnomatematika.

Definisi etnomatematika pertama kali diungkapkan oleh D’Ambrosio (1984) sebagai berikut: "Ethnomathematics is the way different cultur group mathematise (count, measure, relate, classify, and infer)". Menurutnya, kata ethno berarti semua fenomena yang membentuk identitas budaya seperti bahasa, dialek, keyakinan, nilai, pakaian, makanan, kebiasaan dan perilaku. Adapun mathematics menjelaskan tentang konsep matematika secara luas meliputi perhitungan, pengukuran, pengurutan pengklasifikasian, dan pengambilan keputusan. Dengan demikian, etnomatematika merupakan penerapan konsep matematika yang dilakukan sekelompok masyarakat dalam budaya yang berbeda. Secara istilah etnomatematika diartikan sebagai: matematika yang dipraktekkan diantara kelompok budaya diidentifikasi seperti masyarakat nasional suku, kelompok buruh, anakanak dari kelompok usia tertentu dan kelas profesional (D'Ambrosio, 1985). Dari definisi tersebut maka ethnomatematika memiliki pengertian yang lebih luas dari hanya sekedar ethno (etnik) melainkan juga sebagai antropology budaya (culture antropology of mathematics) dari matematika dan pendidikan matematika.

Indonesia merupakan salah satu negara dengan kekayaan budaya yang melimpah. Salah budaya yang cukup disoroti oleh dunia internasional adalah batik. Pada tanggal 2 Oktober 2009, UNESCO menetapkan batik sebagai warisan budaya milik Indonesia yang patut dibanggakan sehingga setiap tanggal 2 Oktober diperingati sebagai hari batik nasional. Batik di Indonesia cukup beragam jenisnya maupun motifnya. Salah satu daerah penghasil industri Batik yang memiliki ciri khas adalah Lebak. Lebak sendiri merupakan nama kabupaten yang ada di Provinsi Banten. Batik Lebak memiliki motif yang khas dan memukau sehingga berbeda dengan motif-motif batik yang ada di Banten. Kekhasan dari motif batik Lebak ini dikarenakan ada nilai-nilai filosofis yang tersirat dalam corak atau motifnya, yang secara khusus mencerminkan budaya daerahnya. Dikutip dari Yollanda (2019) ada sebanyak 12 motif Batik Lebak mendapatkan sertifikat Hak Kekayaan Intelektual (HKI) yang diserahkan oleh Kementerian Hukum dan Hak Asasi Manusia (HAM) Provinsi Banten kepada Bupati Lebak pada tanggal pada 25 Januari 2016. Pada 2 Desember 2016 yang merupakan Hari Jadi Kabupaten Lebak ke-187, 12 motif Batik Lebak resmi diluncurkan kepada masyarakat Kabupaten Lebak. 
Jurnal Lebesgue : Jurnal Ilmiah Pendidikan Matematika, Matematika dan Statistika

Isnaini Mahuda

Volume 1, No. 1, April 2020 hal.29-38

Penelitian tentang eksplorasi etnomatematika telah banyak dilakukan oleh para peneliti terdahulu. Diantara topik-topik penelitian eksplorasi etnomatematika yang sudah ada yaitu eksplorasi etnomatematika pada batik Trusmi Cirebon oleh Arwanto (2017:40), penggunaan etnomatematika pada karya seni batik Indramayu Oleh Sudirman dkk (2017:74), eksplorasi geometris pada motif batik Pasedahan Suropati oleh Ulum dkk (2017:70), belajar matematika dari Batik Jlamprang oleh Muttaqin dkk (2018:41) dan telah banyak penelitian lain yang membahas tentang eksplorasi etnomatematika pada berbagai jenis batik atau ragam seni lainnya. Hasil dari penelitian tersebut menunjukkan bahwa dalam berbagai jenis batik sebagai obyek penelitian terkandung unsur-unsur matematika seperti konsep geometri bidang, transformasi (refleksi, translasi, rotasi, dilatasi), titik, garis, serta konsep kesebangunan dan kekongruenan.

\section{METODE PENELITIAN}

Metode yang digunakan dalam penelitian ini adalah metode deskriptif-kualitatif dengan pendekatan etnografi. Penelitian kualitatif menurut Arikunto (2006: 193) menyebutkan bahwa penelitian kualitatif merupakan penelitian deskriptif karena penelitian ini berusaha menggambarkan data dengan kata-kata atau kalimat yang dipisahkan menurut kategori untuk memeroleh simpulan. Bungin menjelaskan (2011:69) penelitian deskriptif-kualitatif merupakan penelitian eksplorasi yang memainkan peranan amat penting dalam menciptakan hipotesis atau pemahaman orang tentang berbagai variabel sosial. Adapun pendekatan etnografi merupakan pendekatan empiris dan teoritis yang bertujuan mendapatkan deskripsi dan analisis mendalam tentang batik Lebak serta nilai-nilai filosofis dan konsep matematisnya berdasarkan hasil observasi yang peneliti lakukan di lapangan. Dalam penelitian ini, pendekatan etnografi digunakan untuk menggambarkan, menjelaskan dan menganalisis nilai-nilai filosofis dan konsep-konsep matematika yang terdapat pada motif batik Lebak.

\section{HASIL DAN PEMBAHASAN}

Hasil dari penelitian ini berupa kajian nilai-nilai filosofis yang terkandung dalam motif pada Batik Lebak dan nilai-nilai matematis berupa konsep matematika seperti konsep simetris, konsep kesebangunan dan kekongruenan serta konsep pada transformasi geometris yang terdiri dari konsep translasi, refleksi, rotasi dan juga dilatasi. Berikut akan dipaparkan nilai-nilai filosofis dan konsep matematis yang terkandung pada motif pada Batik Lebak: 
Jurnal Lebesgue : Jurnal Ilmiah Pendidikan Matematika, Matematika dan Statistika

Isnaini Mahuda

Volume 1, No. 1, April 2020 hal.29-38

1. Nilai filosofi dan Konsep Matematis pada Batik Lebak Motif Kahuripan Baduy

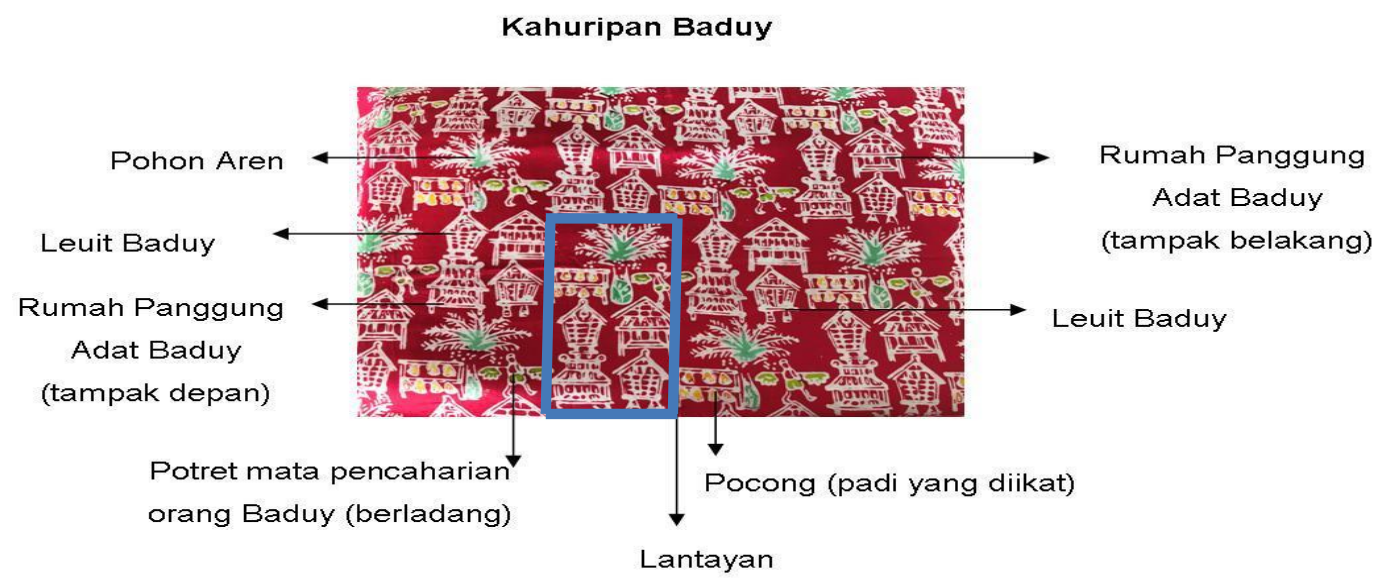

Gambar 1. Batik Lebak Motif Kahirupan Baduy

Seperti namanya yaitu "Kahirupan Baduy" yang berarti kehidupan Baduy, motif ini memiliki nilai filosofi yaitu melambangkan kehidupan yang bersahaja dengan alam dan kental dengan budaya. Suku Baduy adalah suku asli yang berada di wilayah Kab. Lebak. Dari motifnya terdapat unsur-unsur kehidupan masyarakatBaduy seperti gambar pohon aren, rumah panggung (tampak depan dan belakang), Leuit, Padi dan Potret mata pencarian masyarakat Baduy.

Jika kita cermati pada gambar 1, motif batik yang terdiri dari sekelompok unsur yang menggambarkan kehidupan Baduy yaitu Pohon Aren, Leuit Baduy, Rumah Panggung (tampak depan dan belakang), Leuit, Padi dan Potret mata pencarian masyarakat Baduy maka bisa kita dapatkan konsep matematika berupa translasi (pergeseran) pada sekelompok unsur tersebut. Misalkan sekelompok unsur gambar tersebut kita letakan pada koordinat cartesius kemudian dari sekelompok unsur tersebut ditranslasi sekian satuan kekanan dan keatas atau translasi dengan vektor $\left(\begin{array}{l}a \\ b\end{array}\right) a, b>0$ seperti pada gambar 1.2 berikut.

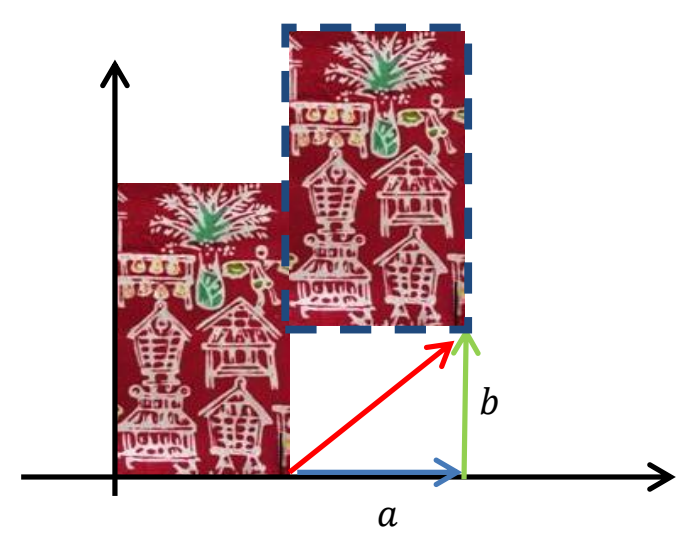

Gambar 1.2. Translasi pada Motif Kahirupan Baduy 
Jurnal Lebesgue : Jurnal Ilmiah Pendidikan Matematika, Matematika dan Statistika

Isnaini Mahuda

Volume 1, No. 1, April 2020 hal.29-38

2. Nilai filosofi dan Konsep Matematis pada Batik Lebak Seren Taun (Cisungsang)

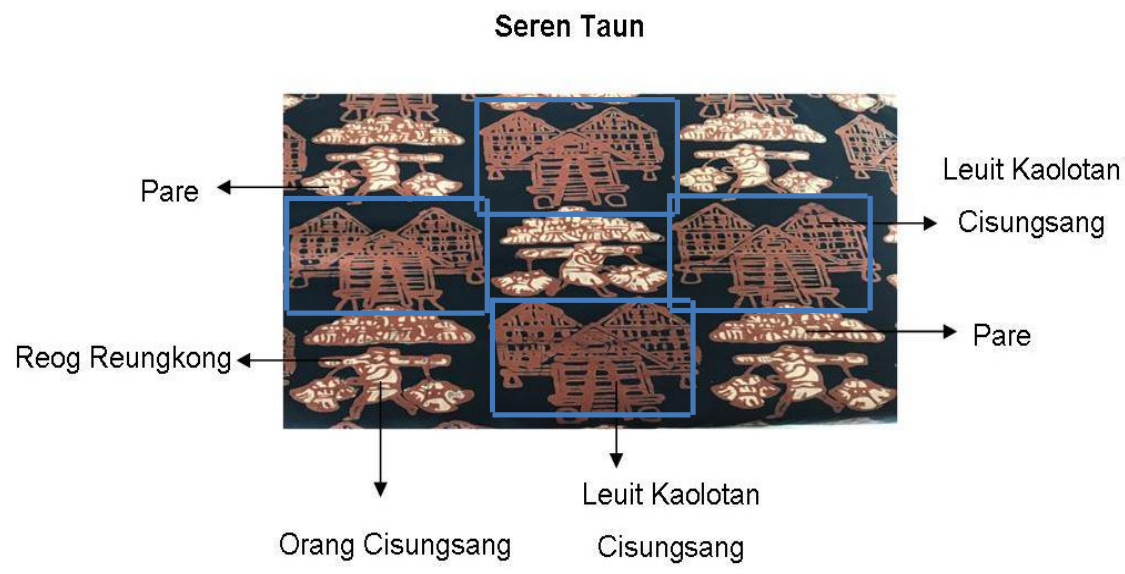

Gambar 2. Batik Lebak Motif Seren Taun

Filosofi dari motif Seren Taun ini melambangkan rasa syukur atas anugerah kenikmatan dari yang Maha Kuasa. Seren Taun merupakan ritual adat masyarakat Cisungsang sebagai wujud syukur atas panen yang mereka dapatkan. Pada motif ini terdapat 3 unsur gambar yaitu Pare (Ikat Padi), Leuit Kaolotan dan Orang Cisungsang.

Nilai matematis pada motif ini yaitu konsep translasi dan kekongruenan. Dengan melakukan translasi pada ketiga unsur gambar pada motif Seren Taun (seperti pada motif Kahirupan Baduy) maka akan diperoleh bentuk yang serupa sesuai dengan sifat pada translasi yaitu tidak merubah ukuran gambar. Sehingga pada motif ini terdapat konsep kekongruenan yaitu memiliki bentuk dan ukuran yang sama pada ketiga unsur gambarnya.

3. Nilai filosofi dan Konsep Matematis pada Batik Lebak motif Angklung Buhun

Angklung Buhun

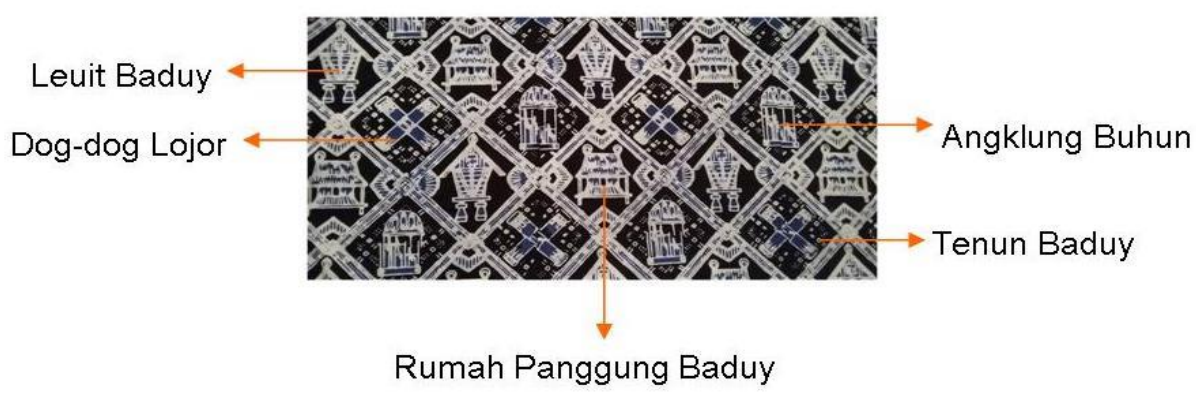

Gambar 3.1. Batik Lebak Motif Angklung Buhun

Motif angklung buhun memiliki nilai filosofi yaitu melambangkan kedinamisan dan kegembiraan. Motif ini terdiri dari unsur-unsur gambar angklung buhun, leuit Baduy, Dog-dog Lojor, rumah Baduy dan tenun Baduy.

Konsep matematis yang terkandung pada motif ini yaitu translasi pada masing-masing unsur gambar yang juga termasuk kedalam konsep kekongruenan dan konsep dilatasi pada segiempat yang 
Jurnal Lebesgue : Jurnal Ilmiah Pendidikan Matematika, Matematika dan Statistika

Isnaini Mahuda

Volume 1, No. 1, April 2020 hal.29-38

menjadi pembatas unsur-unsur gambar pada motif ini. Jika digambarkan pada koordinat Cartesius maka segiempat kecil (berwarna merah) apabila dilatasi dengan pusat $(0,0)$ dengan faktor skala $k>0$ diperoleh segiempat besar (berwarna biru) seperti pada gambar 3.2 berikut.

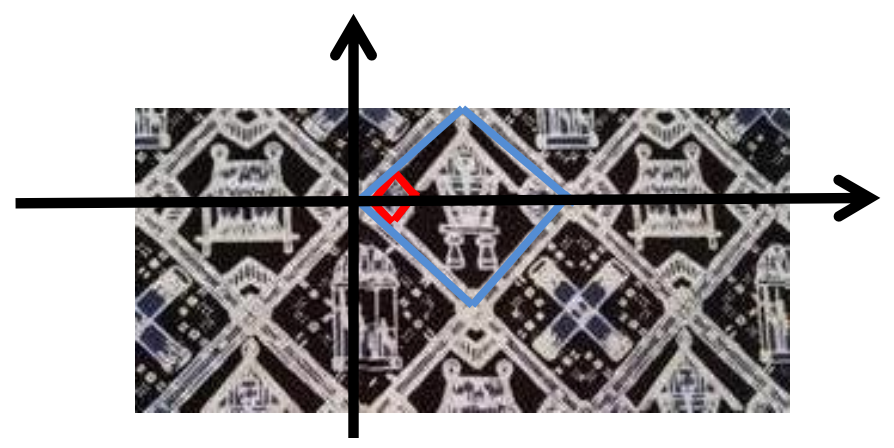

Gambar 3.2. Dilatasi pada Motif Angklung Buhun

4. Batik Lebak Motif Rangkasbitung

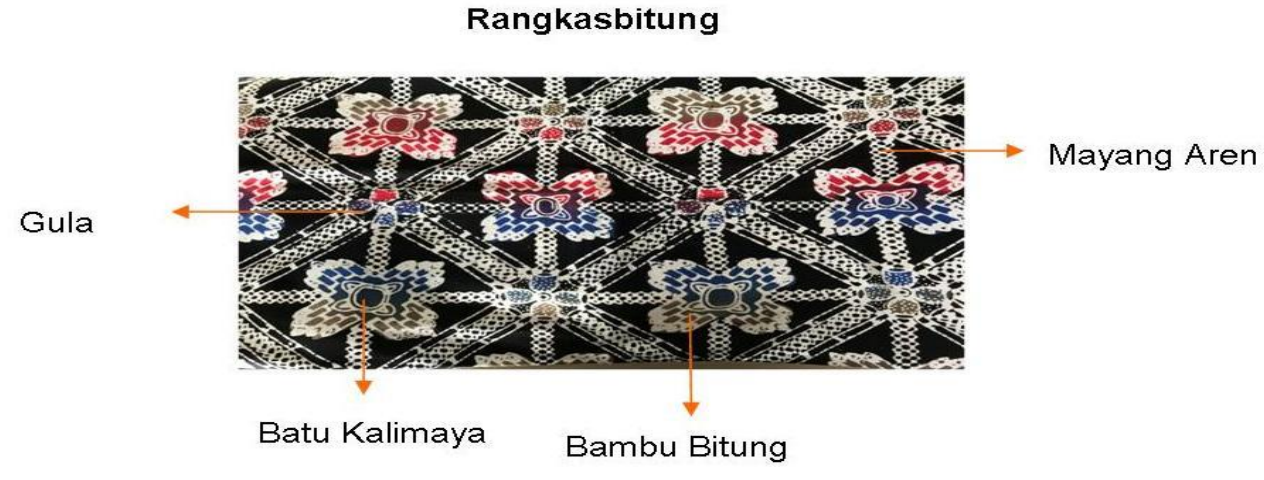

Gambar 4.1. Batik Lebak Motif Angklung Buhun

Motif Rangkasbitung memiliki nilai filosofis yaitu melambangkan ketertiban, keteraturan dan harmonisasi. Unsur gambar pada motif ni terdiri dari gula, batu kalimaya, bambu Bitung dan mayang aren. Rangkasbitung sendiri merupakan ibukota dari Kabupaten Lebak.

Nilai matematis yang terlihat pada motif ini adalah konsep refleksi (pencerminan). Jika digambarkan pada koordinat Cartesius maka sumbu tegak (sumbu-y) menjadi sumbu pencerminannya. Perhatikan gambar 4.2 berikut.

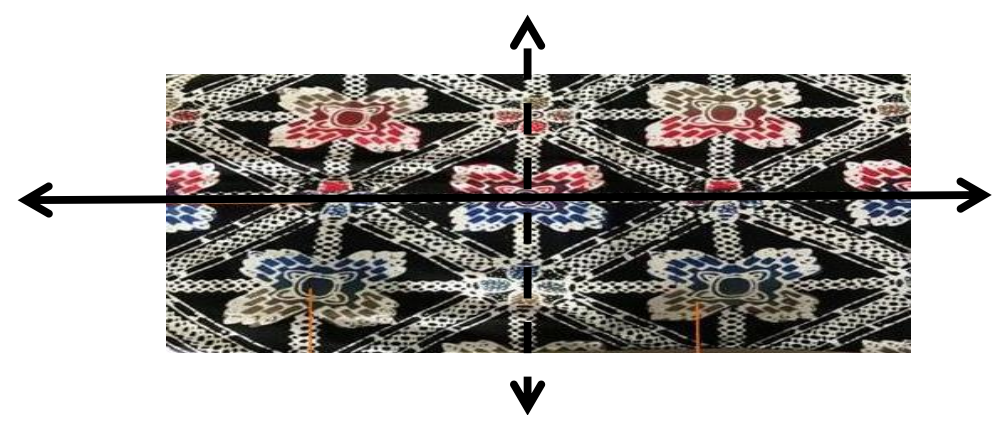

Gambar 4.2. Refleksi pada Motif Angklung Buhun 
Jurnal Lebesgue : Jurnal Ilmiah Pendidikan Matematika, Matematika dan Statistika

Isnaini Mahuda

Volume 1, No. 1, April 2020 hal.29-38

5. Nilai Filosofi dan Konsep Matematis pada Batik Lebak Motif Gula Sakojor

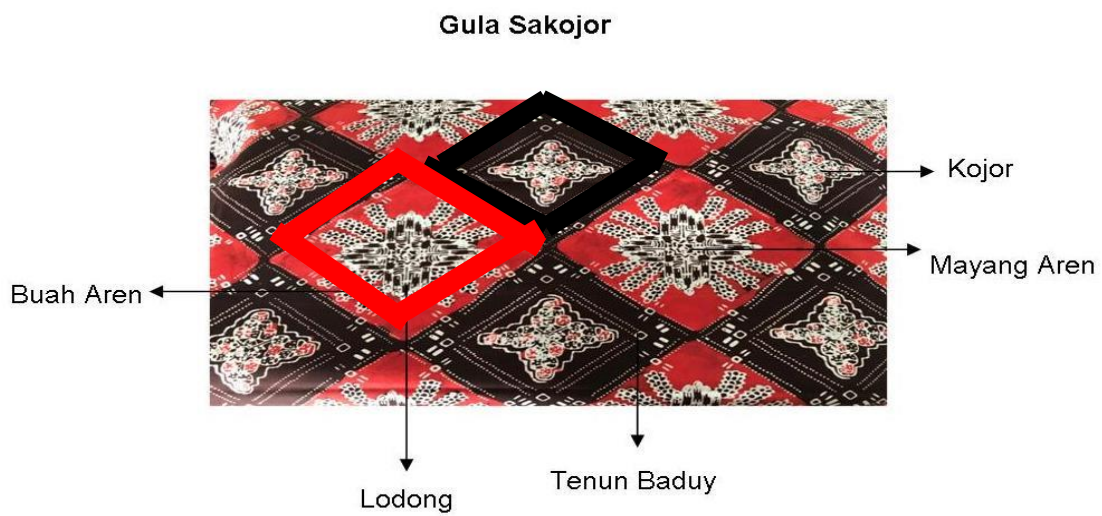

Gambar 5. Batik Lebak Motif Gula Sakojor

Batik Lebak motif gula sakojor terdiri dari unsur-unsur gambar seperti buah aren, lodong, tenun Baduy, Kojor dan Mayang Aren. Nilai filosofis pada motif ini melambangkan sifat kegotongroyongan dalam ikatan kekeluargaan yang saling melindungi dan saling menjaga. Adapun nilai matematis yang terkandung di dalam motif ini adalah konsep kesebangunan antara segiempat hitam dengan segiempat merah pada gambar 5 di atas.

6. Nilai Filosofi dan Konsep Matematis pada Batik Lebak Motif Sadulur

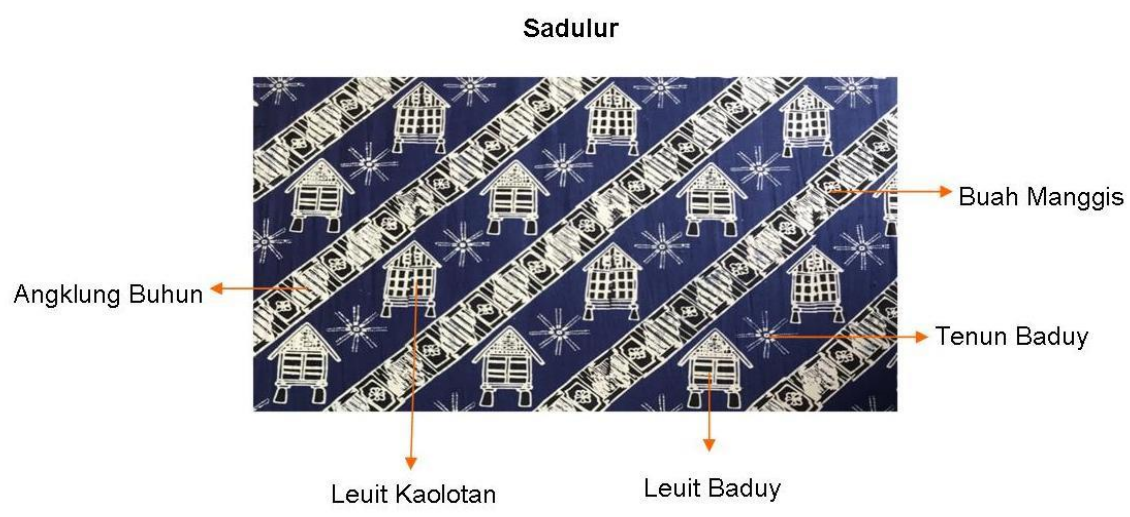

Gambar 6.1 Batik Lebak Motif Gula Sadulur

Sadulur merupakan bahasa sunda yang artinya keluarga. Batik Lebak dengan motif Sadulur tentunya memiliki nilai filosofis yang melambangkan kekeluargaan, kebersahajaan dan kebersamaan. Unsur-unsur yang terdapat pada motif Sadulur ini terdiri dari gambar Angklung Buhun, Leuit Kaolotan, Leuit Baduy, Buah Mangga dan Tenun Baduy. Sedangkan nilai matematis yang terkandung 
Jurnal Lebesgue : Jurnal Ilmiah Pendidikan Matematika, Matematika dan Statistika

Isnaini Mahuda

Volume 1, No. 1, April 2020 hal.29-38

di dalam motif ini adalah konsep translasi (pergeseran) sekian satuan ke kanan atau bisa dinyatakan dengan vektor $\left(\begin{array}{l}b \\ 0\end{array}\right), b>0$

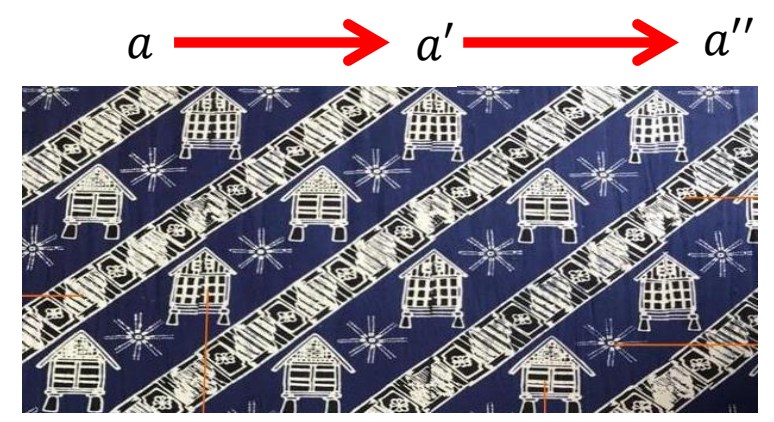

Gambar 6.2 Translasi pada Motif Gula Sadulur

Perhatikan gambar 6.2 , posisi a ditranslasikan dengan vektor $\left(\begin{array}{l}b \\ 0\end{array}\right)$ menjadi $a^{\prime}$ kemudian dilanjutkan dengan translasi pada vektor yang sama menghasilkan posisi $a^{\prime \prime}$

7. Nilai Filosofi dan Konsep Matematis pada Batik Lebak Motif Pare Sapocong

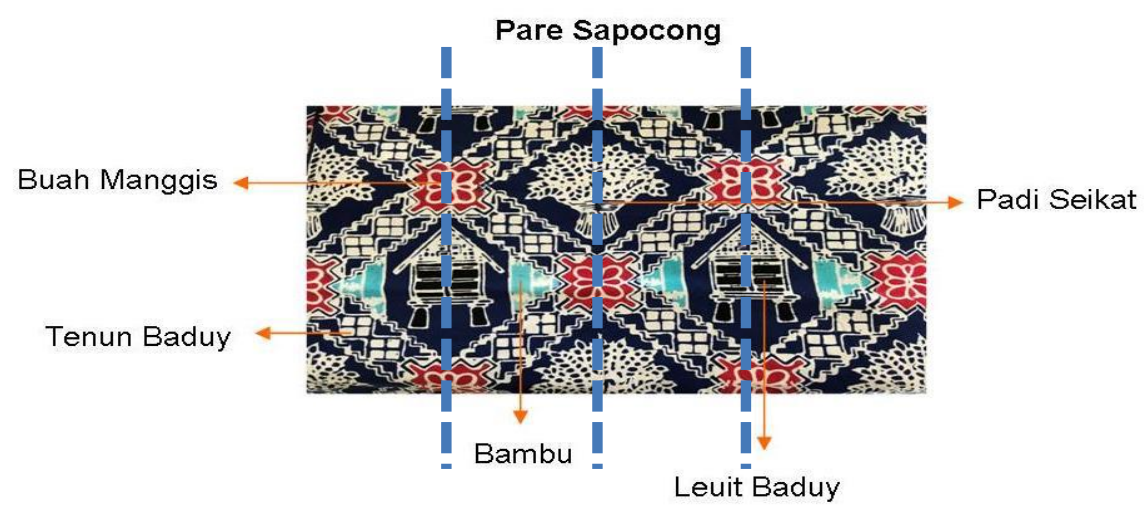

Gambar 7 Batik Lebak Motif Pare Sapocong

Pare Sapocong merupakan frase dalam bahasa sunda yang artinya Padi Seikat. Nilai filosofis pada motif ini melambangkan sumber kemakmuran hidup dengan ikatan persatuan dan kerendahan hati. Unsur-unsur pada motif ini terdiri dari gambar buah manggis, tenun Baduy, padi seikat, bambu dan Leuit Baduy. Adapun konsep matematis dalam motif ini adalah adanya bentuk yang simetris dengan sumbu simetris yaitu garis tegak berwarna biru yang dapat dilihat pada gambar 7 di atas.

8. Nilai Filosofi dan Konsep Matematis pada Batik Lebak Motif Caruluk Saruntuy

Caruluk Saruntuy

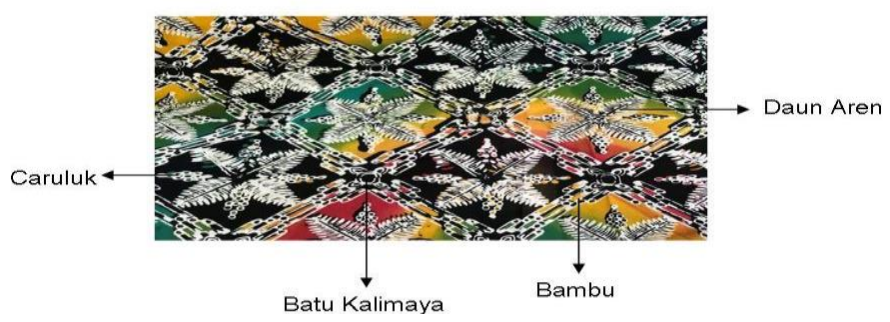

Gambar 8.1 Batik Lebak Motif Caruluk 
Jurnal Lebesgue : Jurnal Ilmiah Pendidikan Matematika, Matematika dan Statistika Isnaini Mahuda

Volume 1, No. 1, April 2020 hal.29-38

Caruluk Saruntuy diambil dari bahasa Sunda, berasal dari kata caruluk yang artinya kolangkaling dan saruntuy yang artinya seuntai. Nilai filosofi pada motif ini melambangkan kehidupan yang penuh kebersamaan meskipun berbeda-beda suku, budaya dan agama namun tetap saling memberikan manfaat bagi sesama. Unsur-unsur pada motif ini terdiri dari gambar Caruluk, Batu Kalimaya, Bambu dan Daun Aren.

Nilai matematis yang terkandung dalam motif ini adalah konsep rotasi (perputaran). Dimana konsep rotasi ini adalah dengan cara memutar motif sesuai dengan sumbunya sejauh $180^{\circ}$ searah jarum jam.

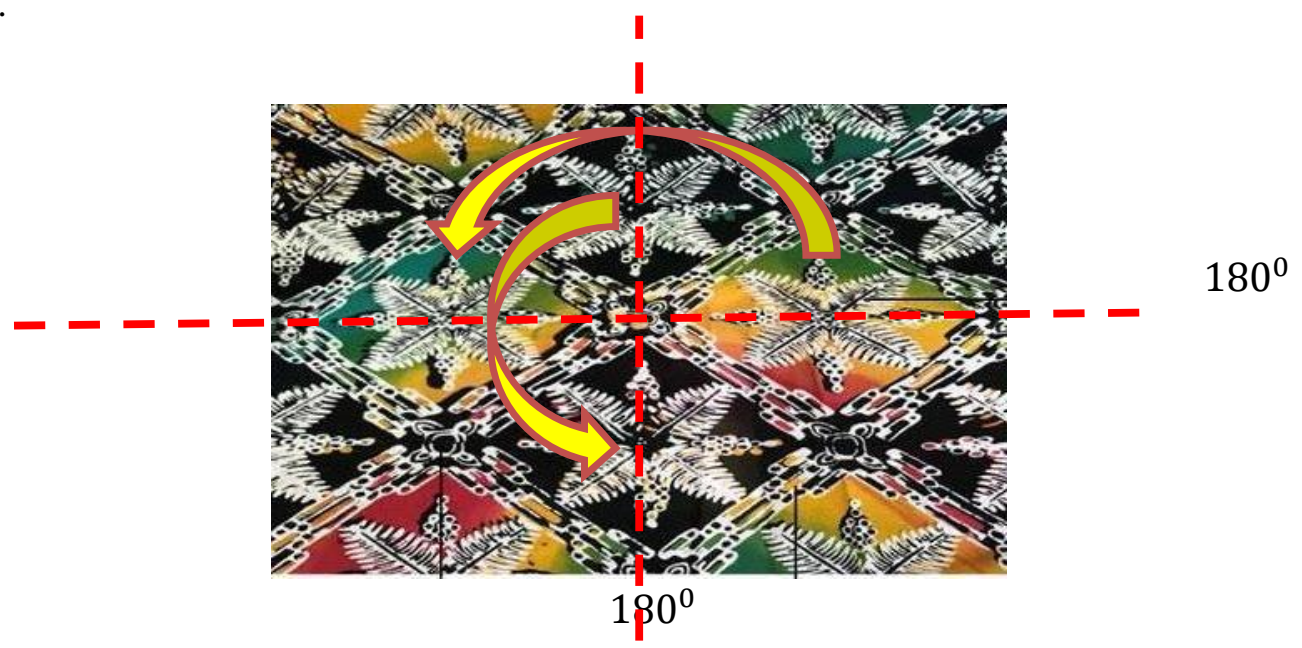

Gambar 8.2 Konsep Rotasi pada Motif Caruluk Saruntuy

\section{KESIMPULAN}

Berdasarkan hasil pembahasan maka diperoleh kesimpulan bahwa motif-motif pada Batik Lebak memiliki nilai filosofis yang ada kaitannya dengan nama motif dan unsur-unsur yang terdapat dalam motif tersebut. Selain itu, motif-motif pada Batik Lebak juga terkandung nilai-nilai matematis yaitu konsep simetris, konsep kesebangunan dan kekongruenan serta konsep pada transformasi geometris yang terdiri dari konsep translasi, refleksi, rotasi dan juga dilatasi. Dari 12 motif Batik Lebak, pada penelitian ini telah dibahas 8 motif yang masing-masing memiliki kaitan dengan konsep matematis yang berbeda. Adapun 4 motif lainnya bisa dijadikan bahan penelitian selanjutnya untuk mengeksplore lebih lanjut nilai filosofis dan nilai matematis yang terkandung di dalam motif Batik Banten tersebut.

\section{DAFTAR PUSTAKA}

Arikunto, Suharsimi. 2006. Prosedur Penelitian Suatu Pendekatan Praktek. Jakarta: Rhineka Cipta. Arwanto, A. 2017. Eksplorasi Etnomatematika Batik Trusmi Cirebon untuk Mengungkap Nilai Filosopi dan Konsep Matematis. Phenomenon: Jurnal Pendidikan MIPA, 7(1), 40-49

Bungin, Burhan. 2011. Penelitian Kualitatif. Jakarta: Prenadamedia Group. 
Jurnal Lebesgue : Jurnal Ilmiah Pendidikan Matematika, Matematika dan Statistika

Isnaini Mahuda

Volume 1, No. 1, April 2020 hal.29-38

D'Ambrosio, U. 1985. Ethnomathematics and Its Place in the History and Pedagogy of Mathematics, $5(1), 44-48$

D'Ambrosio. 1984. "The Intercultural transmission of mathematics knowledge: Effect on mathematical education", Unicamp, Campinas.

Muttaqin, dkk. 2018. Belajar Matematika dari Batik Jlamprang. Prosiding Seminar Nasional Universitas Pekalongan, Vol. 1, No. 1, 41-48

Octavitri, Yollanda . 2019. Analisis Semiotika Pada Motif Batik Lebak Sebagai Upaya Pelestarian Dan Salah Satu Alternatif Bahan Ajar Bahasa Indonesia. Prosiding Seminar Tahunan Linguistik UPI.

Sudirman dkk. 2017. Penggunaan Etnomatematik Pada Karya Seni Batik Indramayu Dalam Pembelajaran Geometri Transformasi. Journal of Mathematics Education, 2(1)

Ulum dkk. 2017. Etnomatematika Pasuruan: Eksplorasi Geometri Untuk Sekolah Dasar Pada Motif Batik Paseadahan Suropati. Prosiding seminar nasional integrasi Matematika dan Nilai Islami, Vol 1, No,1 70-78 